\title{
P154: Sanitize the vehicle
}

\author{
S Dudziak', E Bradshaw ${ }^{2 *}$, L Joseph-Massiah², J Clark ${ }^{3}$ \\ From 2nd International Conference on Prevention and Infection Control (ICPIC 2013) \\ Geneva, Switzerland. 25-28 June 2013
}

\section{Introduction}

In 2011 driven by our growing concern regarding delivery of care related to infection control and the transmission of infections a hand hygiene project was initiated.

\section{Objectives}

Increase product accessibility at point of care

Improved knowledge of hand hygiene and overall infection control processes

Increase in hand hygiene compliance

\section{Methods}

A review of the following items was completed using the LEAN methodology, the 5 "Why".

- System Change -Reviewed location of alcohol-based hand rub at point of care, reviewed accessibility of alcohol-based hand rub to Patients in wheelchair, reviewed accessibility to water soap and towels, reviewed accessibility to hand moisturizers, Interdisciplinary team involvement.

- Training / Education -Family, Patients, staff, visitors, and outside contractors were trained on the moments of hand hygiene and correct procedures for hand rubbing and hand washing, Trained staff to complete hand hygiene observation audits, Staff reviews utilization of gloves, All staff watched a hand hygiene video.

- Evaluation and feedback - Assessed staffs perception of hand hygiene - thru focused groups and surveys, Hand hygiene focused observation audits were completed prior to initiating the project and post implementation, Completed environmental Infection control audits to supplement infection control processes overall.

- Reminders in the workplace -Poster were posted in public areas, audit results were posted in the quality board for all to see.
- Institutional safety climate -Nurtured a culture of Patients safety, Implemented Patients hand hygiene champions on each floor, Involved Patients and Family council.

\section{Results}

- Baseline hand observation audits were compiled and repeated every 3 months. Increase in hand hygiene from $67 \%$ to $96 \%$ (increase of $29 \%$ )

- No outbreaks in 2011, 2012

\section{Conclusion}

This project showed a benefit for the Patients, staff and the community at large.

\section{Disclosure of interest}

None declared.

\section{Author details}

${ }^{1}$ Revera Inc, Mississauga, Canada. ${ }^{2}$ Revera Inc, Toronto, Canada. ${ }^{3}$ Revera Inc,

Ridgetown, Canada.

Published: 20 June 2013

\section{References}

1. A Guide to the Implementation of the WHO. Multimodal Hand Hygiene Improvement Strategy 2009.

2. Health Canada: It's Your Health. The benefits of Hand Washing 2010 Available at: http://www.hc-sc.gc.ca/hl-vs/alt_formats/pacrb-dgapcr/pdf/iyhvsv/diseases-maladies/hands-mains-eng.pd.

3. Nicolle Lindsay E: Preventing Infections in Non-Hospital Settings: LongTerm Care. CDC; 2001, available at: http://www.cdc.gov/ncidod/eid/ vol7no2/nicolle.htm.

doi:10.1186/2047-2994-2-S1-P154

Cite this article as: Dudziak et al:: P154: Sanitize the vehicle. Antimicrobial Resistance and Infection Control 2013 2(Suppl 1):P154.

${ }^{2}$ Revera Inc, Toronto, Canada

Full list of author information is available at the end of the article

C 2013 Dudziak et al; licensee BioMed Central Ltd. This is an Open Access article distributed under the terms of the Creative Commons 